\title{
Orientation Characteristics of Single Crystal Superalloys with Different Preparation Methods
}

\author{
Yang Chubin ${ }^{1,2}, \quad$ Liu Lin', Luo Ning ${ }^{2}, \quad$ Han Baojun², Zhang Xiaolian², \\ Jun $^{1}, \quad$ Fu Hengzhi ${ }^{1}$
}

Zhang

${ }^{1}$ State Key Laboratory of Solidification Processing, Northwestern Polytechnical University, Xi'an 710072, China; ${ }^{2}$ Jiangxi Engineering Research Center for Magnesium Alloys, Gannan Normal University, Ganzhou 341000, China

\begin{abstract}
Single crystal superalloys have been prepared separately by a grain selector and a seeding technique in a high temperature gradient directional solidification furnace. The orientation characteristics were measured by XRD. Results indicate that for the grain selector method, the crystal solidification begins at the cooling plate with random nucleation, and through mutual competitive growth at the starter block. The grains enter the spiral selector, and finally the single crystal superalloys which are close to <001> direction are obtained. By the seeding technique, by epitaxial growth of partially melted seed crystals, single crystal superalloys which have the same orientation as the seed crystal are obtained.
\end{abstract}

Key words: directional solidification; crystal orientation; single crystal superalloys; grain selector; seeding technique

Single crystal superalloys have been applied as the critical high-temperature structural materials of advanced aero-engine ${ }^{[1]}$. D'Souza et $\mathrm{al}^{[2]}$ pointed out that when the single crystal with $<001\rangle$ direction is parallel to the specimen's longitudinal axis, the thermal stresses are reduced, which greatly improves high temperature performance of the castings. It is expected that during the preparation of single crystal superalloys, castings with preferred orientation will be obtained. Walton and Chalmers ${ }^{[3]}$ have reported that the preferred orientation $<001>$ of single crystal superalloys is the fastest growing direction; thus during the directional solidification process, it can weed out other grains very easily and be preserved. During the actual process of directional solidification, because of the changes in the preparation method, solidification parameters and the relative positional relationship of the grains, the preferred orientation of single crystals is often not fully consistent with the direction of heat flow, and even single crystals with non-preferred orientations will be obtained. As a result, high temperature performance of single crystal castings will be affected ${ }^{[4]}$. Studies on crystal orientation characteristics during the single crystal preparation process have attracted a large number of scholars around the world.

A grain selector and a seeding technique are the methods employed to obtain single crystal superalloys. In order to obtain single crystals which can meet the orientation requirements, the studies were focused on the structure of the crystal selector. Carter et $\mathrm{al}^{[5]}$ simulated the grain selection during the solidification of single crystal superalloy castings and the results indicated that only when the length of the starter block was greater than $20 \mathrm{~mm}$ or more, other grains were possibly eliminated and single crystals can be obtained. The results obtained by Gao et al ${ }^{[6]}$ showed that the competitive growth of grains at the starter block affected not only the selection of single crystals, but also the orientation. Esaka et $\mathrm{al}^{[7]}$ applied an engineering model to the single crystal casting process; it indicated that

Received date: April 15, 2016

Foundation item: National Natural Science Foundation of China $(51331005,51171151,51464002)$; The Fund of the State Key Laboratory of Solidification Processing in NWPU (201408)

Corresponding author: Yang Chubin, Ph. D., State Key Laboratory of Solidification Processing, Northwestern Polytechnical University, Xi’an 710072, P. R. China, Tel: 0086-29-88492227, E-mail: yangchubin831012@163.com 
the parameters of the pigtail, such as the angle, width and length, affected the yield rate of the single crystal. Dai et $\mathrm{al}^{[8]}$ studied the effect of spiral design on grain selection during investment casting through a series of experiments. It was found that the spiral design effectively reduced the grain number but was not able to optimize axial grain orientations during solidification. For the seeding technique, the cut seed crystals that met the orientation requirements deposited at the bottom of the master alloy, and were partially melted after pouring liquid metal. The crystals grew along the same crystal orientation as the seed crystals. Jackson et $\mathrm{al}^{[9]}$ studied the origin of equiaxed zone in castings and found that when the seeding technique was adopted to prepare single crystals, the directional solidification in the interface between the semi-solid seed and the molten alloy (the melt-back mush) could be the origin of defective grains that were highly misoriented from the desired seed orientation. Stanford et $\mathrm{al}^{[10]}$ also found that small islands of random orientation were observed throughout the melted-back semi-solid by the quenching technique for the CMSX-4 superalloy. The results of competitive growth between the defective grains and the seed crystal affected the crystal orientation.

In the present paper, single crystal superalloys were prepared separately by the grain selector and the seeding technique in a high temperature gradient directional solidification furnace. XRD was used to measure the orientation and the deviation angle of single crystals, and the characteristics of the crystal orientation under different preparation methods were comparatively analyzed, which could provide a reference for the study and control of single crystal orientation.

\section{Experiment}

First generation nickel-based single crystal superalloys DD407 were used, of which the nominal composition (mass fraction, \%) was: Ni-7.82Cr-5.34Co-2.25Mo-4.88W6.02Al-1.94Ti-3.49Ta. The modified Bridgman directional solidification furnace was employed. During the preparation of single crystals with the grain selector, geometric parameters of the spiral grain selector were based on the findings of Gao et $\mathrm{al}^{[11]}$. When single crystals were prepared with the seeding technique, in order to obtain seed crystals which can meet the requirements, the orientation of the seed crystal was measured and cut, as shown in Fig.1, where $\theta$ represents the orientation of the deviation angle of the single crystal and $\theta_{\text {seed }}$ represents the orientation of the deviation angle of the seed crystals which were cut from the single crystal.

\section{Results}

\subsection{Single crystals prepared by grain selector}

2.1.1 Grain structure evolution
Grain structure evolution within the starter block was observed by macrostructure and microstructure observation. Fig.2a shows the macrostructure of the longitudinal section of the starter block, while Fig.2b, $2 \mathrm{c}$ and $2 \mathrm{~d}$ show the optical microstructure of different locations at the longitudinal section of the starter block. It can be observed that the grains with random orientation at the chill plate, through competitive growth, shift to columnar structures. After the solidification process, the grains with preferred orientation are gradually in a dominant position because of competitive growth, and the grains with a larger deviation angle are eliminated, as shown in Fig.2c. When reaching the top of the starter block, the remaining grains which have gone through competitive growth are mainly columnar crystals with preferred orientation and small angular deviation from the axial direction, as shown in Fig.2d.

Fig. 3 shows the dendritic structures of cross sections at different locations of the grain selector. Fig.3a shows a schematic view of the grain selector and Fig. $3 b \sim 3 e$ show a cross-sectional view of the dendritic structures of corresponding

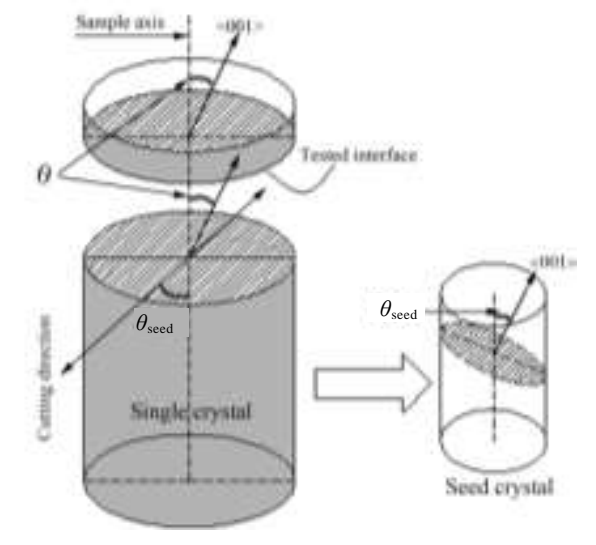

Fig.1 Schematic diagram of the seed crystal cut from the single crystal

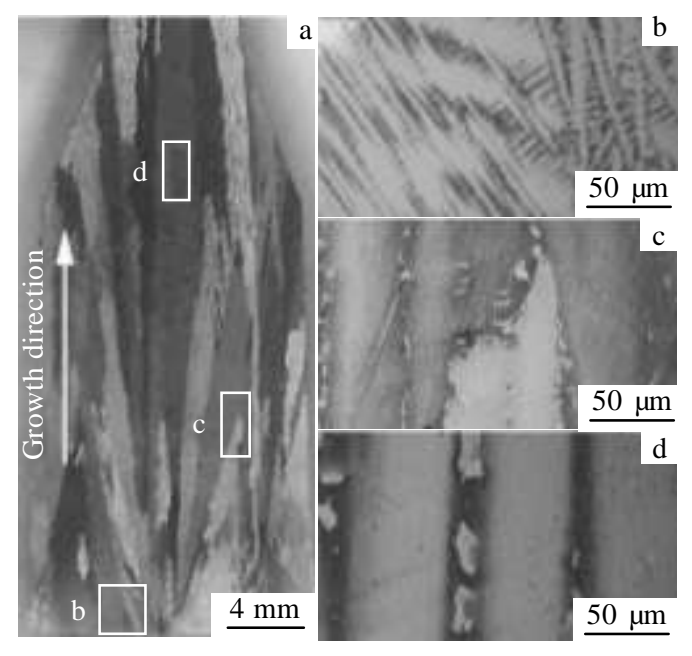

Fig.2 Macrostructure of longitudinal section of starter block (a) and corresponding microstructures $(b \sim d)$ in Fig.2a ( $V=100$ $\mu \mathrm{m} / \mathrm{s})$ 
positions in Fig.3a. After the nucleation of grains at the bottom of the starter block, grains with different orientations grow competitively. In the middle section of the starter block, it could be observed that dendrites with different orientations are distributed randomly (Fig.3b). At the top of the starter block, there are still some dendrites with different orientations. The competitive growth at the starter block could not guarantee that only one grain would be obtained, as shown in Fig.3c. After grains enter into the spiral selector, dendrites are arranged more neatly; and one single crystal grain would be obtained at the location of $d$. At the top of the seeding segment, only one grain with a very neatly-arranged dendritic structure (as shown in Fig.3e) is allowed to enter. All the primary dendrites and their side branches have four-fold symmetry. The dendrite arms show regular cruciform.

\subsubsection{Orientation characteristics}

In order to determine whether single crystals were obtained and their corresponding deviation angle after the selecting process in the grain selector, we sectioned the top of the starter block of the specimen, and then measured it by XRD. The results are shown in Fig.4a. Zhao et al ${ }^{[12]}$ used $\mathrm{XRD}$ to measure the orientation of single crystal superalloys AM3. The results indicated that if two symmetrical butterfly peaks appeared, then the specimen was a single crystal. The orientation deviation angle was defined by $\theta=\left(\theta_{2}-\theta_{1}\right) / 2$, where $\theta_{1}$ stands for the first diffraction peak and $\theta_{2}$ for the second diffraction peak. The results for the orientation deviation angle of all the specimens are shown in Fig.4b, where it could be observed that when the single crystal is prepared by spiral grain selector, the preferred orientation $\langle 001\rangle$ could be obtained and a small deviation angle is observed $\left(<15^{\circ}\right)$. The single crystal in specimen 7 has the preferred orientation, but its deviation angle reaches $23^{\circ}$.

\subsection{Single crystals prepared by seeding technique}

\subsubsection{Grain structure evolution}

Fig. 5 shows the initial transition region microstructure of the seed crystals with different deviation angles during the directional solidification process, including the unmelted seed, the interface and the new epitaxial grown dendrites. It could be seen that the dendritic morphology of the seed crystals plays a decisive role in the morphology of the new dendrites, and the deviation angle of the new dendrite remains substantially the same as that of the seed crystal, as shown in Fig.5b. The primary dendrites grow along the $<001>$ orientation and the secondary dendrites are normal to the primary dendrite, which is irrespective of the deviation angle of the seed crystal. However, the dendrites grow rapidly and are more developed at the face-flow side, thus blocking the evolution of dendrites at the back-flow side when the seed crystal has a large deviation angle, as shown in Fig.5b. Therefore, the dendrite morphologies form "V" patterns because of continuous side-branching.

\subsubsection{Orientation characteristics}

XRD measurements were performed on the crystal orientation of seed crystals and the corresponding single crystals. In order to indicate the variations of the deviation angle between the seed crystal and the single crystal, the following equation was used: $\Delta \theta=\theta_{\text {seed }}-\theta_{\text {crystal }}$, wherein $\theta_{\text {seed }}$ is the deviation angle of the seed crystals while $\theta_{\text {crystal }}$ is the deviation angle of the single crystal. By XRD measurements on all specimens, the relationship between $\Delta \theta$ and $\theta_{\text {seed }}$ was calculated and it is shown in Fig.6. It can be seen that when a seed crystal has preferred orientation $\langle 001\rangle$, the prepared single crystal still has $\langle 001\rangle$ orientation. The variation of the deviation angle is small. When a seed crystal has non-preferred orientation $\langle 011\rangle$, and the prepared single
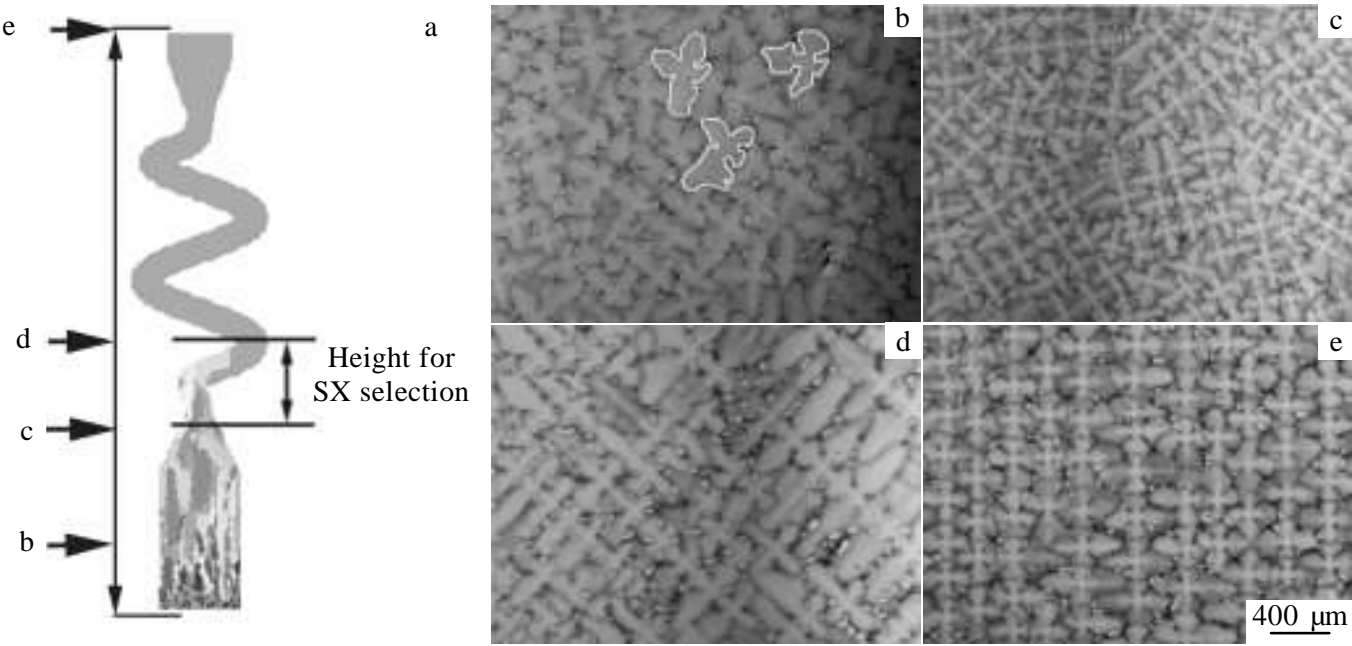

Fig.3 Schematic view of the grain selector (a) and cross-sectional view of the dendritic structures (b e) of corresponding positions in Fig. $3 \mathrm{a}(V=100 \mu \mathrm{m} / \mathrm{s})$ 

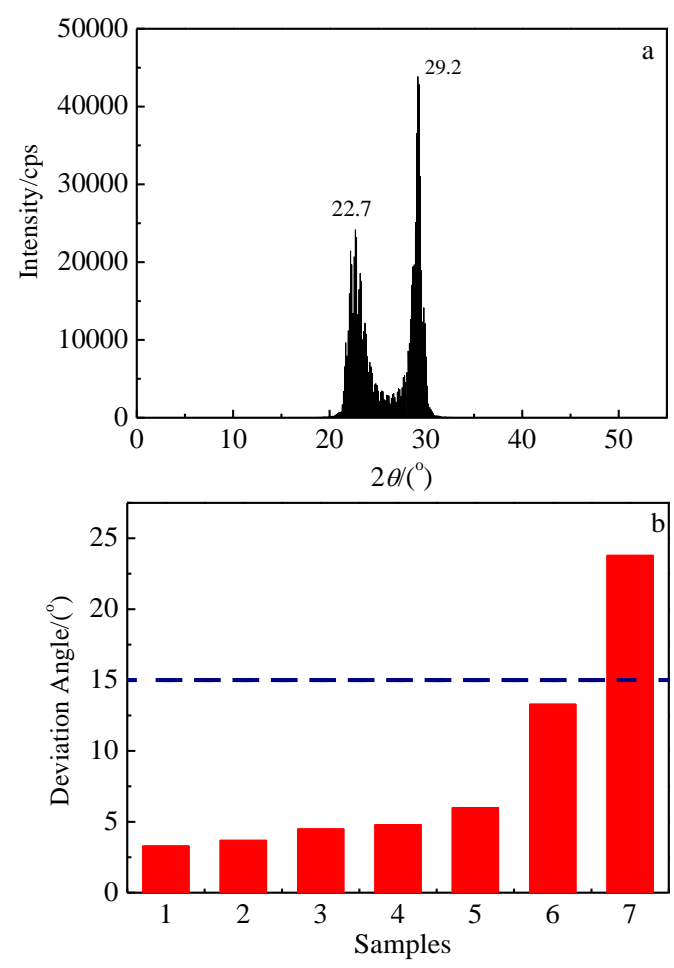

Fig.4 RO-XRD pattern (a) from $<001>$ plane of the crystals and deviation angle (b) of single crystal for different samples prepared by grain selector

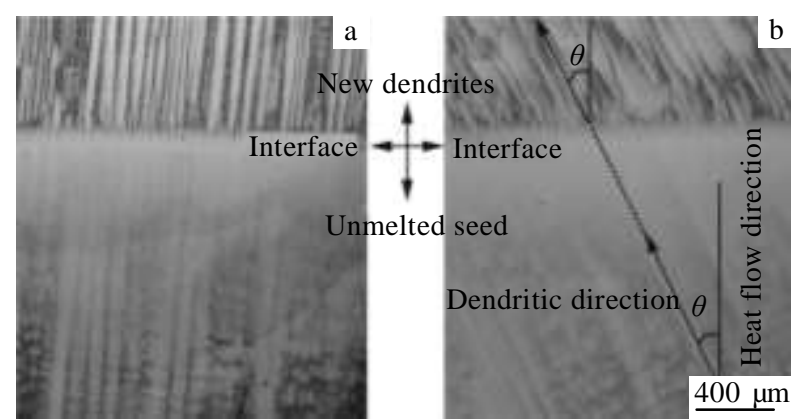

Fig.5 Optical microstructures of three different transitional zones for the seeds with different deviation angles at $V=100 \mu \mathrm{m} / \mathrm{s}$ : (a) $\theta_{\text {seed }}=3^{\circ}$ and (b) $\theta_{\text {seed }}=27^{\circ}$

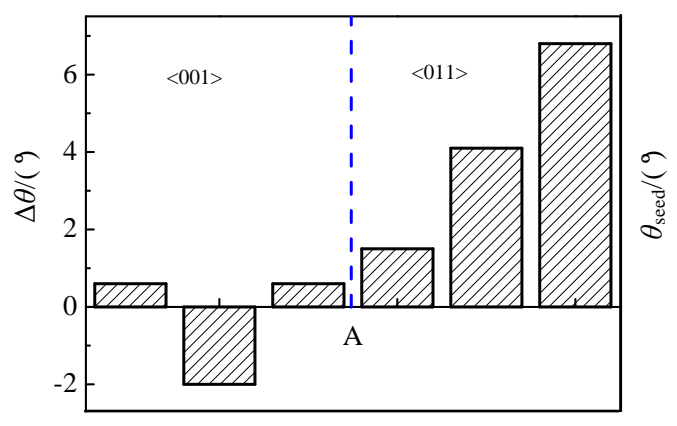

Fig.6 Relationship between $\Delta \theta$ and $\theta_{\text {seed }}$ for the different samples prepared by the seeding technique crystal still has non-preferred orientation, then the variation of the deviation angle would increase with the increase of the deviation angle of the seed crystals.

\section{Discussion}

After the competitive growth of grains at the starter block, the remaining grains go through a crystal selecting process at the spiral selector, and mono-crystalline structures are acquired. As the results shown in Fig.4, it can be seen that the single crystals with the preferred orientation $<001\rangle$ and a small deviation angle are obtained. The results obtained by Gao et $\mathrm{al}^{[6]}$ and Dai et $\mathrm{al}^{[8]}$ indicated that for the single crystal prepared by spiral grain selector, its crystal orientation had a close relationship with the grains' competitive growth at the starter block and the parameters of the spiral selector. The single crystal with a larger deviation angle $\left(23^{\circ}\right)$ is observed in sample 7 in Fig.4, because the unfavorably oriented dendrites are able to overgrow the favorably oriented dendrites under some specific conditions and a larger deviation angle single crystal is obtained. Zhou et al ${ }^{[13]}$ investigated the structure evolution of bicrystal samples during directional solidification. It was found that in the case of converging dendrites, the unfavorably oriented dendrites were able to overgrow the favorably oriented dendrites. Similar results were obtained for competitive growth between the differently orientated dendrites by phase-field method and ProCAST $^{[14-16]}$. Gao et al ${ }^{[17]}$ found that the dendrites which were close to the inner side of the spiral channel had sufficient space to grow, and during the competitive growth process, they could remain through the branching of the dendrites. Similar results were obtained through simulation by Seo et $\mathrm{al}^{[18]}$. Accordingly, when a single crystal is prepared by the grain selector, the crystal orientation deviation angle is co-determined by the grains' competitive growth and the structure of the spiral selector. Due to its certain randomness, single crystal superalloys with larger deviation angles are produced, which is consistent with the results in Fig.4.

When single crystal superalloys are prepared by grain selector, the obtained single crystal generally have the preferred orientation. In practical applications, single crystals with particular orientations are required, and the seeding technique would be needed to control the orientation. As shown in Fig.6, it could be concluded that when single crystals are prepared by the seeding technique, single crystals which have the same orientation as the seed crystal could be obtained, but its deviation angle could not be accurately controlled. The previous studies ${ }^{[19]}$ have indicated that when the orientation deviation angle was large, the stray grains would be formed at the diverging $\langle 001\rangle$ corner of the mold wall. In addition, at the re-melting interface, due to broken dendrites, the changes in the seed crystal's re-melting zone 
and other parameters, stray grains which had inconsistent orientation were easy to introduce ${ }^{[9]}$. Therefore, in order to prevent the formation of stray grains and effectively control crystal orientation of the single crystal, Stanford et $\mathrm{al}^{[20]}$ combined the seed crystal method with the crystal selecting method, and placed the prepared seed crystals at the bottom of the starter block to prepare single crystal superalloys. Toloraiya et $\mathrm{al}^{[21]}$ also found that when the seed crystals and the grain selector techniques were combined, the method showed the advantages of both techniques, i.e. the high structural perfection and the possibility of fabricating single crystals with specified spatial orientation.

\section{Conclusions}

1) Single crystal superalloys are successfully obtained by grain selection. The orientation characteristics of single crystal superalloys are the preferred orientation $\langle 001\rangle$ and a small deviation angle $\left(<15^{\circ}\right)$.

2) The dendrite morphology and crystal orientation of the single crystal superalloys are consistent with that of the seed crystal.

3) The deviation angle of the crystal orientation cannot be accurately controlled by the seeding technique, especially when the seed crystals has non-preferred orientation. The change in the deviation angle increases with the increase in the deviation angle of the seed crystal.

\section{References}

1 Yu Z H, Liu L, Zhao X B et al. Rare Metal Materials and Engineering[J], 2011, 40(8): 1407 (in Chinese)

2 D'Souza N, Newell M, Devendra K et al. Materials Science and Engineering $A[\mathrm{~J}], 2005,413-414: 567$

3 Walton D, Chalmers B. Transactions of the Metallurgical Society of AIME[J], 1959, 215: 447

4 Wang C S, Zhang J, Liu L et al. Rare Metal Materials and Engineering[J], 2011, 40(2): 307 (in Chinese)
5 Carter P, Cox D C, Gandin C A et al. Materials Science and Engineering $A[\mathrm{~J}], 2000,280(2): 233$

6 Gao S F, Liu L, Wang N et al. Metallurgical and Materials Transactions A[J], 2012, 43(10): 3767

7 Esaka H, Shinozuka K, Tamura M. Materials Science and Engineering $A[\mathrm{~J}], 2005$, 413-414: 151

8 Dai H J, D'Souza N, Dong H B. Metallurgical and Materials Transactions A[J], 2011, 42(11): 3430

9 Jackson K A, Hunt J D, Uhlmann D R et al. Transactions of the Metallurgical Society of AIME[J], 1966, 236: 149

10 Stanford N, Djakovic A, Shollock B A et al. Superalloys 2004[C]. Warrendale: TMS, 2004: 719

11 Gao S F, Liu L, Zhao X B et al. Materials Science and Technology[J], 2011, 27(12): 1783

12 Zhao X B, Liu L, Yu Z H et al. Rare Metal Materials and Engineering [J], 2009, 38(7): 1280 (in Chinese)

13 Zhou Y Z, Volek A, Green N R. Acta Materialia[J], 2008, 56(11): 2631

14 Li J J, Wang Z J, Wang Y Q et al. Acta Materialia[J], 2012, 60(4): 1478

15 Meng X B, Lu Q, Zhang X L et al. Acta Materialia[J], 2012, 60(9): 3965

16 Yang C B, Liu L, Zhao X B et al. Journal of Alloys and Compounds[J], 2013, 578: 577

17 Gao Sifeng, Liu Lin, Wang Ning et al. Acta Metallurgica Sinica[J], 2011, 47(10): 1251 (in Chinese)

18 Seo S M, Kim I S, Lee J H et al. Metals Materials International [J], 2009, 15(3): 391

19 Yang C B, Liu L, Zhao X B et al. Applied Physics A[J], 2014, 114(3): 979

20 Stanford N, Djakovic A, Shollock B A et al. Scripta Materialia[J], 2004, 50(1): 159

21 Toloraiya V N, Orekhov N G, Kablov E N. Metal Science and Heat Treatment $[\mathrm{J}], 2002,44(7-8): 279$

\title{
不同制备方法对单晶高温合金取向特征的影响
}

\author{
杨初斌 ${ }^{1,2}$, 刘 林 $^{1}$, 罗 宁 $^{2}$, 韩宝军 ${ }^{2}$, 张小联 ${ }^{2}$, 张 军 $^{1}$, 傅恒志 ${ }^{1}$ \\ (1. 西北工业大学 凝固技术国家重点实验室, 陕西 西安 710072) \\ (2. 赣南师范学院 江西省镁合金工程研究中心，江西 赣州 341000)
}

摘 要: 在高温度梯度定向凝固炉中分别采用选晶法和籽晶法制备单晶高温合金, 并采用XRD测定单晶的取向特征。结果表明, 采用选 晶法制备单晶高温合金时，在激冷板上随机形核的晶粒经过起晶段的竞争生长和螺旋段的选晶作用后，最终获得具有择优取向 $<001>$ 的 单晶。采用籽晶法制备单晶高温合金时, 通过重熔籽晶的外延生长, 所获得的单晶取向与籽晶取向保持一致。

关键词：定向凝固；晶体取向；单晶高温合金；选晶法；籽晶法

作者简介: 杨初斌, 男, 1982 年生, 博士, 西北工业大学凝固技术国家重点实验室, 陕西 西安 710072, 电话: 029-88492227, E-mail: yangchubin831012@163.com 